\title{
Risk factors associated with the development of dental caries in Bulgarian children
}

\author{
Dobrinka Damyanova $^{1}$, Valentina Velikova ${ }^{2}$ \\ ${ }^{1}$ Department of Pediatric Dental Medicine, Faculty of Dental Medicine, Medical University of Varna, Bulgaria \\ ${ }^{2}$ Department of Management and Administration, Faculty of Management, University of Economics, Bulgaria
}

\section{Article Info \\ Article history: \\ Received Sep 30, 2020 \\ Revised Feb 16, 2021 \\ Accepted Mar 10, 2021}

\section{Keywords:}

Dental care

Dental caries

Oral health

Primary teeth

Surveys and questionnaires

\begin{abstract}
The purpose of this study was to examine the risk factors associated with the development of dental caries in children in Bulgaria. The research has been carried out at the Faculty of Dental Medicine, in the period 2015-2016, with the permission of the University Scientific Research Committee and informed consent signed by each parent. The subject of observation was parents of children from Varna region in Bulgaria. The results were statistically processed with SPSS v.20.0, using variation and comparison (chi-square) analyzes. For significance level we assume $\mathrm{p}<0.05$. The volume of observation encompasses 100 persons. Units of observation are patients aged three to six years with the need for prevention and treatment of dental caries of the primary dentition. The registration was done in a specially developed questionnaire, including 22 questions, each with the possibility of more than one answer. In processing the obtained data, Student's criterion was used to compare the mean values of two independent samples. In a comparative analysis of the results, we found that $71.01 \%$ of children aged three to six years visit a dentist, and patients use fluoride only in the form of toothpaste containing fluoride. When studying the knowledge and behavior of parents in the direction of risk factors for the development of dental caries and oral prophylaxis, need for a new approach of pediatric dentists has been found, focused on programming preventive and non-invasive treatment of children according to their individual needs.
\end{abstract}

This is an open access article under the CC BY-SA license.

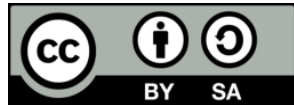

\section{Corresponding Author:}

Dobrinka Damyanova

Department of Pediatric Dental Medicine, Faculty of Dental Medicine

Medical University of Varna

84, Tsar Osvoboditel, 9000 Varna, Bulgaria

Email: dr_damyanova@abv.bg

\section{INTRODUCTION}

Healthy temporary teeth support the functions of the chewing apparatus, the correct pronunciation of words, have aesthetic significance and are important for the development of permanent teeth. Caries of temporary teeth is the most common cause of impairment of these functions [1]. Improper behavior gives rise to a process that allows bacterial involvement and realization of carious lesions [2]. The correction in a child's behavior helps to self-control the oral environment and prevents the development of carious lesions [3]. Methods for non-operative and operative preventive treatment have been developed, requiring changes in the protocol for treatment of caries in temporary teeth [4].

According to Shin Hye-Sun et al. the questionnaire developed by them on the child's perceptions was independently related to dental caries. The authors came to the conclusion that the questionnaire for self- 
assessment of children's perceptions can be a practical tool for assessing the subjective health of the oral cavity among Korean children aged 8 to 14 years [5].

Scientists such as Suma Sog, H. P. et al. make an assessment of the existing knowledge, attitudes and practices of "oral cavity health" in the prevention of early childhood caries (ECC) among parents of children in the city of Belagavi [6]. Other authors, such as Aimée and Dame [7] conducted a meta-analysis of their results. This review and meta-analysis were undertaken by researchers to assess the responsiveness of validated quality of life questionnaires related to oral cavity health related to dental caries interventions in children, adolescents, and young patients.

The findings of authors such as Villalobos-Galvis F.H. et al. suggest that the modified 36-position model has satisfactory reliability and validity of a number of factors studied by them. Therefore, a research screening model can be a valuable tool for screening perceptions for oral cavity diseases [8], [9]. Numerous public health studies have been conducted on the development and growth of pediatric, adolescent, and adult patients [10]-[17].

Robinson et al. conducted a study in 2007 with the aim to determine whether questionnaires could be used to replace clinical trials by comparing the described and clinically examined status of dental caries and the treatment needs in a sample from adults living in East London, UK. The authors conclude that selfassessment is not useful for assessing and planning individual dental care needs. These findings are useful for assessing treatment and diagnostic needs for the community [18], [19].

Dimova-Gabrovska and co-authors conducted a study in 2019 with the aim: to investigate the use of laboratory crowns in children used for casting in the daily practice of dentists in Bulgaria. The obtained results are used for planning new clinical and treatment goals [20]-[26]. Researchers are developing guidelines for clinical application by all prosthetic dentists and general dentistry professionals [22], [26].

\section{RESEARCH METHOD}

The purpose of this study is to examine the risk factors associated with the development of dental caries in children in Bulgaria.

\subsection{Materials and methods}

For the purpose of the research we applied a sociological (survey) method. The research has been carried out at the Faculty of Dental Medicine, in the period 2015-2016, with the permission of the University Scientific Research Committee and informed consent signed by each parent. In the survey, the object of observation was parents of children from Varna region. The volume of observation comprised 100 participants. Units of observation are patients aged three to six years with the need for prevention and treatment of dental caries of the temporary dentition. The direct individual anonymous questionnaire was filled in by the parents of patients in dental practices on the territory of the city of Varna and clinical halls of the Faculty of Dental Medicine-Varna. The registration was done in a specially developed questionnaire, including 22 questions, each with the possibility of more than one answer. The signs of observation are: Gender, age, medical history; Caries diagnosis; Oral hygiene habits; Motivation for preventive examinations and non-invasive treatment; Remedies prescribed by a dentist to increase hygiene, prevention and noninvasive treatment of caries. The results were statistically processed with SPSS v.20.0, using variation and comparison (chi-square) analyzes. For significance level we assume $\mathrm{p}<0.05$.

Respondents express an opinion on: the diagnosis of caries, oral hygiene habits of the child, motivation for preventive examinations and non-invasive treatment, tools prescribed by the dentist to improve hygiene, prevention and non-invasive treatment of caries.

\section{RESULTS AND DISCUSSION}

The results show that $5 \%$ of the mothers of the studied children had bad habits during pregnancy. In $100 \%$ of the examined mothers the pregnancy passed without complications and $100 \%$ of them did not have any diseases during the pregnancy. Only $3 \%$ of the children surveyed were born prematurely, with $98 \%$ of the children being born with normal weight and $2 \%$ of the children being born with low weight.

In the Medical history of the surveyed parents we received the following data: One of the children suffers from hematological disease, one of the children has an allergy to antibiotics from the group of penicillins, one of the children suffers from allergy to dust and mites, two of the children suffer from allergic rhinitis, one of the children suffers from kidney disease, and one of the children is treated with the drug: LThyroxine.

The results show that parents are aware of the need for preventive examinations of children aged three to six years. Although $69 \%$ of the parents state that the visit to the dentist is consecutive and they 
regularly observe the prophylactic examinations of their children, $31 \%$ indicate that they have not taken the child for a prophylactic dental examination yet at the age of three. Dental practices are attended by $8 \%$ of children for examination in one month, and $20 \%$ in three months. The highest percentage of parents $-72 \%$ visit a dental office for prevention and treatment of their children every six months, or two times a year. On the one hand, these results may be related to the practices in the city of Varna, which have contracts with the National Health Insurance Fund, but on the other hand shows that a higher percentage of children in the survey are at high risk of dental caries.

Regarding question № 13 "Do you have difficulties in recognizing your child's dental caries?," parents openly share the difficulties with the diagnosis - Dental caries of temporary teeth, as $54.0 \%$ of them do not recognize and do not have the necessary knowledge about the diagnosis. $46.0 \%$ of the respondents declare knowledge and experience in diagnosing caries of temporary teeth as shown Figure 1.

From question №14 "Does your child have dental caries?", a very high percentage of parents report child dental caries disease of the temporary teeth $-75.0 \%$ and only $25.0 \%$ of children do not get sick as shown Figure 2.

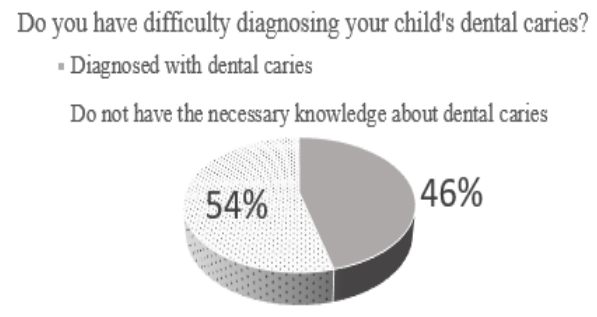

Figure 1. Do you have difficulty diagnosing your child's dental caries?

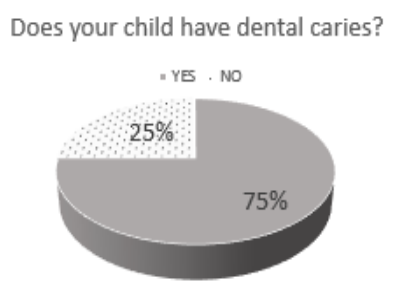

Figure 2. Does your child have dental caries?

Parents who have already had cases of dental caries in children recognize the symptoms much more easily than those who encounter the problem for the first time $(\mathrm{p}<0.05)$. To question № 15, "Has your child had injuries?," $3 \%$ of parents reported injuries to their children's teeth, $3 \%$ of children had facial injuries and $3 \%$ had oral and/or dental injuries as shown Figure 3.

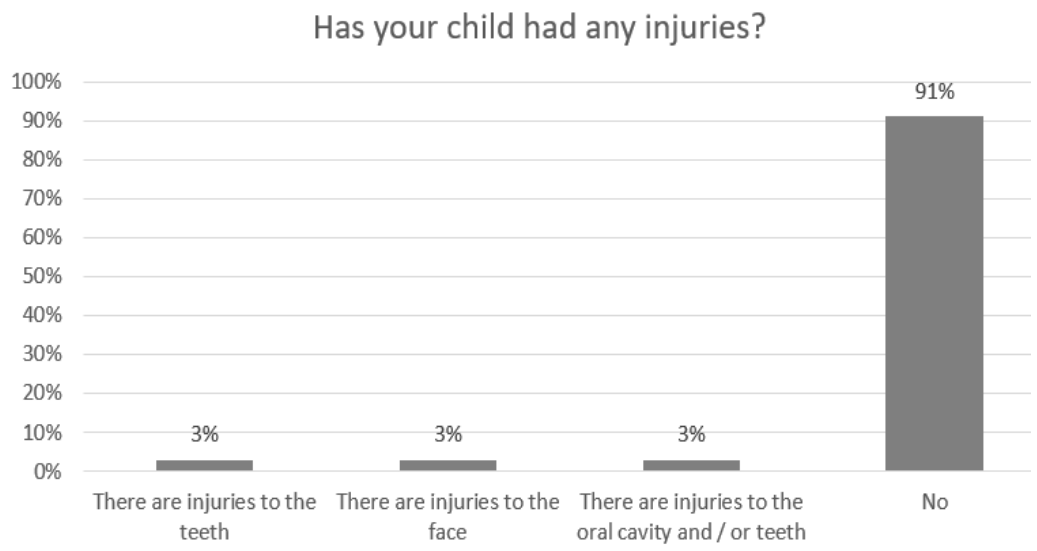

Figure 3. Has your child had injuries?

To question № 16 about the motivation of children and their behavior in a fearful clinical environment, the respondents showed knowledge of motivating children $-81 \%$ of children do not have fearful behavior, $13 \%$ have little fear and $6 \%$ of parents and children have problems attending prevention and treatment in dental clinics and practices as shown Figure 4. 


\section{Is your child afraid of dental treatment?}

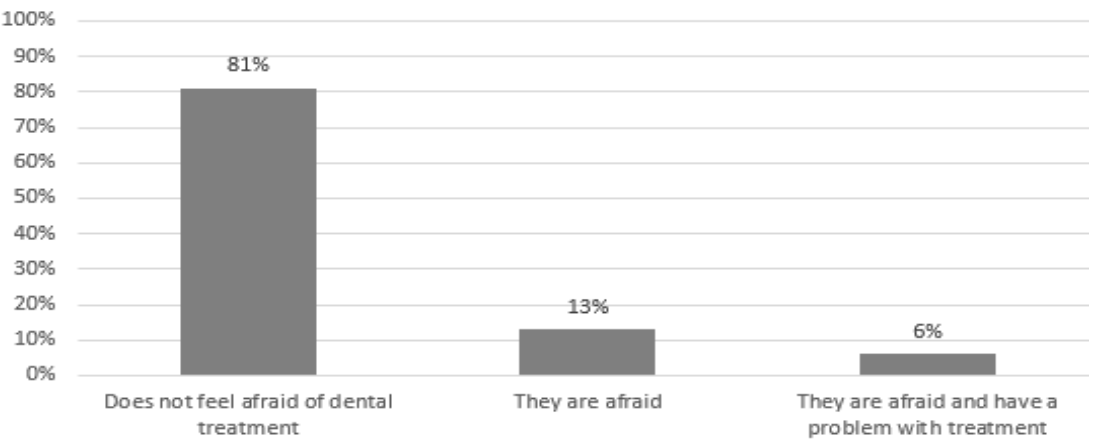

Figure 4. Is your child afraid of dental treatment?

Question № 17 "Does the child have bad habits," $1 \%$ of the parents report the habit of sucking lips and cheeks, $11 \%$ of the habit of biting nails by children, $6 \%$ gnash their teeth, $4 \%$ of children have the habit of sucking their thumb(s), and $1 \%$ of children fall asleep at this age with a bottle of milk/juice. It is noteworthy that none of the respondents indicated the harmful habit of sucking a pacifier by the child. Probably by the age of three parents have enough knowledge and skills and the use of a pacifier stops much earlier than the age we studied.

The most popular is the double brushing of teeth by children (54\% of the surveyed parents), $17 \%$ of children brush them once a day, $3 \%$ of children three times a day, $2 \%$ rarely during the week and $2 \%$ of children brush their teeth their when they remember during the day as shwon Figure 5.

How many times a day does your child brush his teeth?

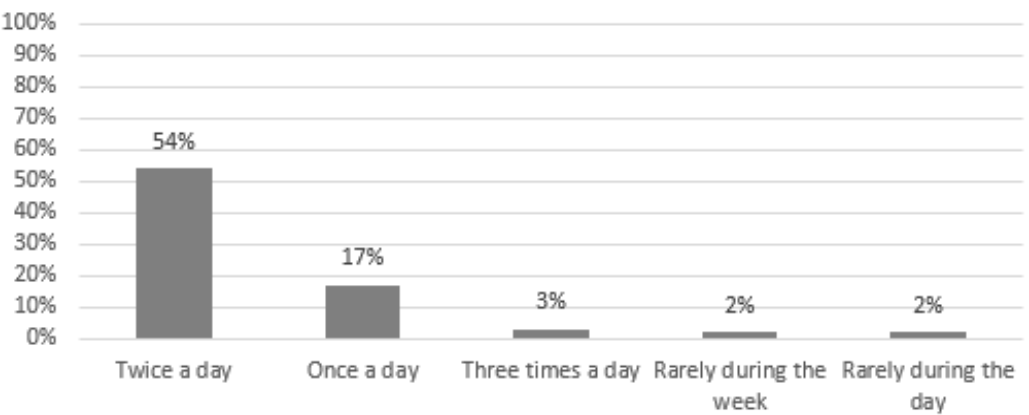

Figure 5. How many times a day does your child brush his teeth?

At the same time, $90 \%$ of children use fluoride toothpaste, $27 \%$ of children aged three to six use low mineral water for drinking fluoride. Only $3 \%$ of children took fluoride containing tablets, and fluoride gels were not used by respondents at home. To question № 20.1, "Does your child use mouthwash and dental floss?," knowledge of water for oral hygiene, as well as their application was demonstrated by $6 \%$ of parents of children over six years. Dental floss is used by $10 \%$ of children aged three to six years, according to their parents.

From the obtained results we can conclude that the most common of the means for personal oral hygiene of children aged three to six years is toothpastes for children with fluoride concentration for the studied age. On the other hand on question № 21, "Has any prophylactic toothpaste been applied to your child's teeth in the dental office? Only $10 \%$ of the surveyed parents report prevention and non-invasive treatment of their children Figure 6 and $10 \%$ of them for the application of prophylactic pastes by their children at home as shown Figure 6. 


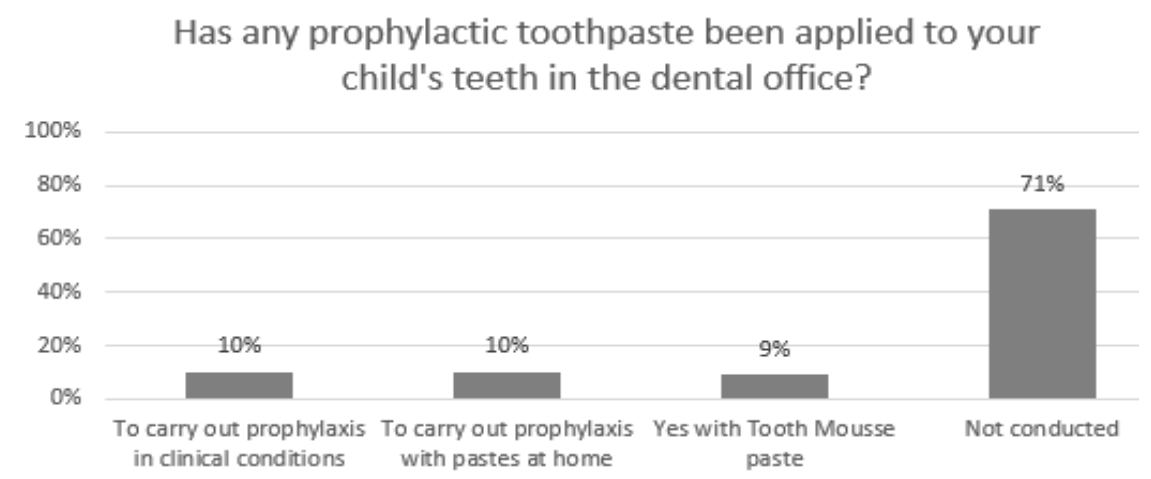

Figure 6. Has any prophylactic toothpaste been applied to your child's teeth in the dental office?

Of the means for remineralization and non-invasive treatment of early enamel lesions at home, respondents apply GC Tooth Mousse 9\% [Tooth Mousse-Bio-available calcium and phosphate, without fluoride, GC] [27]. For this reason, there is a need for a new approach and practice of pediatric dentists, oriented in practice, meeting the expectations of parents to more preventive and non-invasive methods of treatment of dental caries of temporary dentition.

In processing the following data, Student's criterion was used to compare the mean values of two independent samples. In a comparative analysis of questions "A visit to the dentist?" And "does your child take fluoride in various forms?" We found that $71.01 \%$ of children aged three to six years visit a dentist, and patients use fluoride only in the form of toothpaste containing fluoride. On the other hand, this result proves the observance of good oral hygiene and knowledge of children's toothpastes with different concentrations of fluoride and insufficient knowledge and application by parents and children of dental floss (90\%) and oral hygiene water (94\%) by six-year-olds. Probably the wide knowledge of children's pastes for oral hygiene is due to advertising and the media, giving constant information to parents.

In a comparative analysis of "questions was there any application of prophylactic pastes on your child's teeth in the dental office?" And "does your child take fluoride in various forms?" We found that $71.84 \%$ of children aged three to six years use only fluoride toothpaste. This shows the ignorance of the parents and the insufficient application by dentists of the preventive and non-operative treatment of the initial caries in the dental practices for the temporary dentition. $90 \%$ of the respondents did not apply prophylactic pastes on the child's teeth, both in the dental office and at home.

\subsection{Discussion}

Dental caries during early childhood is a multifactorial disease. Early childhood caries (ECC) is a term used to describe dental caries in the primary dentition of young children [28]. The presence of one or more decayed that can be non-cavitated or cavitated, missing due to caries, or filled tooth surfaces in any primary tooth in a child. Dental caries are caused by the interaction between the bacteria which produces acid, the carbohydrate substrate (frequently sucrose) and the hosts susceptibility [29]. The primary pathogen recognised for ECC is Streptococcus Mutans. Along with S. mutans ECC also reports significant association with S. parasanguinis, S. salivarius, Lactobacillus casei and Actinomyces viscosus [30].

Prevention: Cessation of habit; Dietary advice [31]; possible use of antimicrobial products; Fluoride application [32]. Infant should not be put to sleep with a bottle (infant should be encouraged to drink from cup); Elimination of a bottle habit can be achieved by gradually reducing the amount of sugar in the bottle by diluting with water. This can be done over several weeks. Alternatively, some parents find it easier to remove the bottle immediately [33].

\section{CONCLUSION}

Based on the data obtained from the survey among patients from the city of Varna and Varna region, the following conclusions can be made: The surveyed parents of children aged three to six years have satisfactory knowledge and habits regarding a number of risk factors for the development of dental caries, concerning the oral health of their children and the maintenance of oral hygiene. No significant difference was found between the respondents in terms of forming an opinion and behavior on key issues related to prevention, oral hygiene and preventive and non-invasive treatment of caries of temporary teeth. The number 
and type of visits to the dental clinic-primarily or consecutively are not factors for change in the methods and means of oral hygiene and preventive and non-invasive treatment of patients. A study of the knowledge and behavior of parents aimed at the direction of risk factors for dental caries and oral prevention revealed the need for a new approach of pediatric dentists, focused on programming preventive and non-invasive treatment of children according to their individual needs. If there are incipient/white spot lesions present then the treatment should proceed with preventative treatment. This includes fluoride application, fissure sealant application, and explanation of causes without assigning blame, education and advice to the parents about cessation of the bad habits causing caries, dietary advice, oral hygiene instruction and tooth brushing instruction.

\section{ACKNOWLEDGEMENTS}

The authors would like to thank Assoc. Prof. Dr. Assia Krasteva-Panova for the support concerning preparation of the inquiry forms and Assoc. Prof. Emanuela Moutafova who contributed to the performance of the statistical analysis.

\section{REFERENCES}

[1] Frencken, J.E et al., "Minimal intervention dentistry for managing dental caries - a review: Report of FDI task group," International Dental Journal, vol. 62, no. 5, pp. 223-43, 2012, doi: 10.1111/idj.12007.

[2] Breaker, R.R., "New insight on the response of bacteria to fluoride," Caries Research, vol. 46, no. 1, pp. 78-81, 2012, doi: $10.1159 / 000336397$.

[3] Damyanova, D et al., "Treatment after illness of early childhood caries - clinical case report," Quest Journals Journal of Medical and Dental Science Research, vol. 4, no. 5, pp. 79-82, 2017.

[4] Ramos-Gomez, Fr. J et al., "Pediatric dental care: prevention and management protocols based on caries risk assessment," Journal California Dental Association, vol. 38, no. 10, pp. 746-761, 2010.

[5] Shin, Hye-Sun et al., "Korean version of child perceptions questionnaire and dental caries among korean children," PLoS One, vol. 10, no. 2, 2015. doi: 10.1371/journal.pone.01160112015.

[6] Suma Sog, H. P et al., "Knowledge, attitude, and practices of oral health care in prevention of early childhood caries among parents of children in Belagavi city: A questionnaire study," Journal Family Medicine Primary Care, vol. 5, no. 2, pp. 286-290, 2016, doi: 10.4103/2249-4863.192332

[7] Aimée, N.R., Damé-T. N., "Responsiveness of oral health-related quality of life questionnaires to dental caries interventions: Systematic review and meta-analysis," Caries Research, vol. 53, no. 6, pp. 585-598, 2019, doi: $10.1159 / 000500855$.

[8] Villalobos-Galvis, F.H., and Mafla, A.C., "Psychometric properties of the revised illness perception questionnaire for oral health," Caries Research, vol. 51, no. 3, pp. 244-254. 2017, doi: 10.1159/000468993.

[9] Moysés, J. S., "Inequalities in oral health and oral health promotion," Brazilian Oral Research, vol. 26, 2012, https://doi.org/10.1590/S1806-83242012000700013

[10] Joseph, J. El., and Shiju, Mathew, "The Efficacy of the integrated child development services in perspective to nutritional condition and growth development," International Journal of Public Health Science, vol. 4, no. 1, pp. 17-20, 2015, doi: http://doi.org/10.11591/ijphs.v4i1.4706.

[11] Cheryl, A. Al., and Lidong, W., "Public Health Promotion: Autonomy of the Emergency Nurse Practitioner," International Journal of Public Health Science, vol. 4, no. 1, pp. 17-20, 2015, doi: http://doi.org/10.11591/ijphs.v4i1.4708.

[12] Farhana, J. Ar et al., "Role of mothers' nutritional knowledge, nutritional factors on the school performance," International Journal of Public Health Science, vol. 4, no. 1, pp. 44-49, 2015, doi: http://doi.org/10.11591/ijphs.v4i1.4710.

[13] Ariyani, Dwi F., and Handayani L., "Contribution Factors on Early Initiation of Breastfeeding," International Journal of Public Health Science, vol. 4, no. 3, pp. 192-196, 2015, doi: http://doi.org/10.11591/ijphs.v4i3.4732.

[14] Agrimon, H. O., and Street, J., "Developing Comprehensive Diabetes Education Materials for Structured Patient Education Programs in Primary Care Setting," International Journal of Public Health Science, vol. 5, no. 1, pp. 16-26, 2016, doi: http://doi.org/10.11591/ijphs.v5i1.4758

[15] Rikawarastuti, R et al., "Periodontal Disease on Pregnant Women (Case Study: Pondok Labu Village, South Jakarta, Indonesia)," International Journal of Public Health Science, vol. 5, no. 2, pp. 170-175, 2016, doi: http://doi.org/10.11591/ijphs.v5i2.4782.

[16] Inayah, L. A et al., "Evaluation of lactation promotion as part of baby friendly hospital," International Journal of Public Health Science, vol. 6, no. 1, pp. 45-50, 2017, doi: 10.11591/.v6i1.6531

[17] Peev, St., and Sabeva, El., "Bone block augmentation - a long-term follow-up," Scripta Scientifica Medicinae Dentalis, vol. 4, no. 2, pp. 29-35, 2018.

[18] Levin, L et al., "The use of a self-report questionnaire for dental health status assessment: a preliminary study," British Dental Journal, vol. 214, no. 5, p. E15, 2013, doi: doi: 10.1038/sj.bdj.2013.224.

[19] Dimova, A et al., "Health systems in Transition," vol. 20, no. 4, 2018. [Online]. Available: http://www.euro.who.int/_data/assets/pdf_file/0005/383054/HiT-Bulgaria-2018-web.pdf?ua=1 
[20] Dimova-Gabrovska et al., "Questionnaire survey of fixed crown prosthetic treatment in children," Journal of $I M A B$, vol. 25, no. 3, pp. 2675-2678, 2019.

[21] Dimova-Gabrovska et al., "Advantages and disadvantages of paediatric crown prosthetic treatment," Journal of $I M A B$, vol. 25, no. 3, pp. 2695-2700, 2019.

[22] Dimova, E., Doichinova, L, and Andreeva-Borisova, R., "Dentists' Awareness of white spot lesions during treatment with fixed orthodontic appliances," Medinform, vol. 7, no. 1, pp. 1156-1164, 2020.

[23] Sokolskaya, M.V et al., "The effect of personal health on the formation of human capital: a metasystem approach," International Journal of Public Health Science (IJPHS), vol. 8, no. 1, pp. 135-142, 2019.

[24] Peckham, St et al., "Health promotion and disease prevention in general practice and primary care: a scoping study," Cambridge core, vol. 18, no. 6, pp. 529-540, 2017.

[25] Zafiropoulos, G., "Educational programmes: Saving money in healthcare," British Journal of Healthcare Management, vol. 21, no. 12, pp. 571-576, 2015.

[26] Damyanova, Dobrinka, "Reporting caries in the stage of destruction - d3mft/s+d4mft/s," IOSR Journal of Dental and Medical Sciences (IOSR-JDMS), vol. 16, no 6(vii), pp. 93-96, 2017.

[27] Tooth Mousse-Bio-available calcium and phosphate, without fluoride, GC EUROPE A.G., 2020. [Online]. Availabe: https://europe.gc.dental/bg BG/products/toothmousse

[28] Hajishengallis, E et al., "Advances in the microbial etiology and pathogenesis of early childhood caries," Molecular Oral Microbiology, vol. 32, no. 1, pp. 24-34, 2017, doi: 10.1111/omi.12152. Epub 2016 Feb 4.

[29] Fakhruddin, K. S., Ngo, H. C, and Samaranayake, L. P, "Cariogenic microbiome and microbiota of the early primary dentition: A contemporary overview”, Oral Disease, vol. 25, no. 4, pp. 982-995, 2019, doi: 10.1111/odi.12932.

[30] Hemadi, A.S., Huang R., Zhou, and Y., Zou, J., "Salivary proteins and microbiota as biomarkers for early childhood caries risk assessment," International Journal Oral Science, vol. 9, no. 11, 2017, doi: 10.1038/ijos.2017.35.

[31] Palmer, C. A et al., "Diet and caries-associated bacteria in severe early childhood caries," Journal Dental Research, vol. 89, no. 11, pp. 1224-9, 2010, doi: 10.1177/0022034510376543.

[32] Damyanova, D and Andreeva-Borisova, R., "Analysis of Therapeutic Efficacy of Clinically Applied Varnish," Dental Research and Oral Health, vol. 1, no. 2, pp. 022-028, 2018, doi: 10.26502/droh.004

[33] Kawashita, Y et al., "Early Childhood Caries," International Journal of Dental, vol. 2011, p. 7, https://doi.org/10.1155/2011/725320 